\title{
Lumbar Intraspinal Meningioma
}

National Cancer Institute

\section{Source}

National Cancer Institute. Lumbar Intraspinal Meningioma. NCI Thesaurus. Code C5298.

A meningioma that arises from the meninges of the lumbar region of the spinal cord. 